\title{
The Community Factor of the Rural Development
}

\author{
Tibor FARKAS*, Dóra KOLTA, Dorsaaf MAAYOUFI
}

\author{
Faculty of Economics and Social Sciences SZIU Gödöllö, Hungary \\ *Corresponding author: Tibor FARKAS e-mail: farkas.tibor.kumacs@gmail.com
}

\section{RESEARCH ARTICLE}

\begin{abstract}
In the study local society and the development possibility of Tomești (Csíkszenttamás) were analysed. The village has been studied primarily in terms of development. One of the most important research questions was (and remains) how local society is fit to engage in rural or local development and what social problems hinder the development. The village camp research included questionnaire surveys, interviews and analysis of photographs, local and official statistical data. With help of the development stories, we try to draw general conclusions about the functioning of endogenous resources and social capital, too. It was demonstrated, that the strong community participation and social capital could compensate the inherited disadvantage and contribute to development. The local conflicts, tensions, party interests could undermine the best development possibilities. We concluded that without a strong local society, the local development initiatives could fail.
\end{abstract}

Keywords: local development; rural development; social capital.

Received: 30 September 2020 Accepted: 26 November 2020 Published: 14 May 2021

DOI:

15835/buasvmcn-hort:2020.0052

(c) (1) (3) 2021 Authors. The papers published in this journal are licensed under the Creative Commons Attribution-NonCommercialNoDerivatives 4.0 International License

\section{INTRODUCTION}

In this study, we assess the social capital of the people living in the village of Tomești, as well as the state and characteristics of the local society. We investigate whether there is a relationship between the state, social capital, and development opportunities of local society. Before the analyzes we describe the research methods and the database. In this study, we analyze the development of Tomești, the obstacles and opportunities for its development. I outline the problems that hinder the developments, the development perspective of the village with the help of the questionnaire survey, the opinions in the literature, and the interviews, and I also mention some problems and development opportunities that need to be solved. The aim of this study is not only to get to know the local society better, but also to examine how and to what extent the local community can be involved in various rural and community development activities. Although a lot of village research took place, in the case of the authors it was the first village research camp in Harghita county.

\section{LITERATURE REVIEW}

The approach and the methods of village research in Hungary changed a lot over the decades. The village researchers in the 1930s explored the villages from a sociographic point of view. After the Second World War traditions of village research were revived especially among ethnographers.

At the end of the 1980s there was a significant change in the approach and method of research. According to various authors (Ludescher, 2009), in this period, 
the sociographic method lost its importance.The organization of research camps at the Faculty of Economic and Social Sciences started at the former Department of Agricultural Sociology. These village research camps focused primarily on the development path and possibilities of different villages. One of the most important research questions was (and remained) how local society is fit to engage in development and what local social problems hinder the development. During the study of local societies and economies we also rely heavily on earlier research on social capital and quality of life research.

A wide range of literature (Orbán-Szántó, 2005; Hanzel-Kassai, 2014; Kulcsár, 2017) suggests how social capital plays an essential role in sustainable rural development. Where social capital is weak there are conflicting values and a lack of trust, which hinder any economic or social development activities. Social capital was first used in international literature in the beginning of the 20th century by Lyda Judson Hanifan (Tömpe, 2007), but it only became widely known in the 1990s. Since then social capital has been given a number of different definitions (Fukuyama, 2001), but there has not been a generally accepted one yet. On the basis of the concepts of Bourdieu (1986), Coleman (1988), Putnam (1993) and Fukuyama (2002), social capital is a mixture of relations, trust, civil social activity and norms regulating social behaviour.

The issue of social capital is increasingly coming to the fore in development studies. Social capital is nothing more than a network of trust-based, mutually benign relationships. Strong social capital presupposes a strong local society where NGOs are intense, communication between people is intense, and there is a high level of trust in each other, strangers, and the institutional system. Social capital is a resource of community. It means relationships between members of the community that are based on trust (see Füzér et al., 2005).

While investigating the community factor of the development we will use the following theoretic grid. Table 1. shows a direct relationship between social capital/subsidiarity and the type of the development. It is suggested, that in the case of high social capital and existing endogen resources there are good opportunities for development.

Table 1. The social-economic characteristics of rural development

\begin{tabular}{cll}
\hline \multirow{2}{*}{ Type of development } & \multicolumn{2}{c}{ Social capital/subsidiarity } \\
\cline { 2 - 3 } Dominantly endogen & $\begin{array}{l}\text { High } \\
\text { based on the cooperation of partners, on the local } \\
\text { community and economy }\end{array}$ & $\begin{array}{l}\text { Lased on the dominant role of local } \\
\text { elite/oligarch }\end{array}$ \\
\hline $\begin{array}{c}\text { Dominantly } \\
\text { exogenous }\end{array}$ & $\begin{array}{l}\text { not organic development characterized with } \\
\text { conflicts }\end{array}$ & $\begin{array}{l}\text { centralized, top down } \\
\text { development }\end{array}$ \\
\hline
\end{tabular}

The authors emphasize Bíró's opinion that highlights the importance of local identity and the status and functions of local communities. He states that their development is important not only for researchers interested in the social processes of the region. In a resource-deficient region, external support, external stimulation and support for development processes is obviously important for local development. But it is as important as the inclusion of endogenous capacities. In order to gradually begin to develop and organize themselves for a settlement in a peripheral situation today, the existence or absence of these local-scale community reserves may be crucial (Bíró, 2002).

\section{APPLIED METHODS AND DATA}

We carried out research on predetermined topics in the village research camp. The main topics of the camps have changed partly, but some topics stayed permanent over the years. Basically, the following methods were used during the research: processing and analysis of data available at the site and in databases, questionnaire surveys, interviewing, and participant observation.

In the course of our research, we relied primarily on the applications of Romanian National Institute of Statistics (INS). Census databases also play an important role in demographic research. Local databases consist of local government registers, state and church registers. We used Excel and SPSS for analysis.

In the questionnaire survey, we asked one member of the household. Sampling is done in a systematic, random manner. Representativeness is also ensured by the appropriate sample size. In case of Tomești, the population size was 2550 inhabitants in less than 800 households. There were filled 300 questionnaires. The sample was slightly shifted toward seniors and women. Frequency distributions were calculated from the data obtained during the research, and the results are presented using diagrams and tables. While analyzing the relationships between metric variables with the help of cross-table analysis, we conducted correlation calculations.

In addition to quantitative research, the collection of qualitative data was equally important. The questionnaire survey revealed who was the authoritative, decision-making, opinion-forming personality of the village. During the interviews, we were primarily looking for the most prominent person in the village. Participant observation is the 
observation of everyday life, work, consumption habits and participation in holidays. Experiences are grouped together at the end of the camp days.

\section{THE DEVELOPMENT OF THE VILLAGE}

Tomești is located in the Ciuc Basin, in its Upper part. The population of the village is 2.600 people. Agriculture has been the basis of the village's livelihood for many centuries, but according to Balázs Orbán, quarrying also took place. On the other hand forestry has always been of great importance. Between the two world wars, craft activity was also significant. According to our interviewees, people worked in the fields in the summer, they had no money, and they cut down forests in the winter. Hemp processing was significant. However, traditional farming has become less and less a secure livelihood since the 1950s.

The socialist type collective farm was formed in 1962: "People were forced to join the collective". Many worked in the collective farm, but the majority became factory workers. Nationalization forced the workers into this local collective farm or more distant industrial jobs (Bălan, Sândominic, Cârța, and Miercurea Ciuc). After 1989, people regained their land, so agriculture and forestry play an important economic role again (Sándor, 2005).

The big restrictions in Romania started in 1983; goods could only be obtained from under the counter. "The system has taught people to steal." In the collective farm, several women worked, where they were producing potatoes. Potato cultivation could be made even ten years ago. At present, EU subsidies encourage farmers to continue pasture farming.

The application of the 18th Land Act and the restitution of land in the village is a serious problem. After 1991, several people received land illegally. Cases are difficult to repair, and restitution is controversial. At the same time, there have been many criticisms of the operation of the common ownership of lands; its assessment is unfavourable in the village, even though it makes a significant contribution to developments.

Today, the adult population of the village can be divided into four major groups in terms of labour force. The first group includes those who farm in Tomești; carry out self-sufficient (self-employed) or market production on a smaller or larger plot of land. Another group - smaller than the previous one - has jobs in other parts of Romania and in Székely Land. The third group belongs to guest workers who take up work abroad, usually in the following countries: Germany, Austria, and Switzerland. The average age of guest workers is increasing, older ones are also leaving for a few months; in two months they earn as much as they would at home in one year. The fourth group includes the elderly and pensioners. Employment is often characterized by seasonality and periodicity.

Unemployment and labour shortage are present in the settlement at the same time. In fact, there are not enough jobs in the village, however, many do not go to work for a minimum wage and others do not want to lose social assistance. This situation can be helped by the industrial zone planned by the municipality, which would provide a solution to this problem in the long run. The village already operates an incubator house on a 6,000-square-foot site where two contractors operate for low rents.

According to Székely (2016), in the Ciuc Basin, local development is still in many cases aimed at filling the gaps accumulated over several decades (building infrastructure, creating the right conditions for community) or strengthening the local community, local identity (events, cultural and social programs, training, etc.). Issues such as strengthening attachment to rural areas, ensuring livelihoods, community well-being and local competitiveness are also beginning to emerge in more and more places.

The development opportunities of the settlement are also strongly shaped by political factors. Tomești was an independent village until 1968, Izvoru Mureșului also belonged to it (later this settlement was attached to Voșlăbeni), and then from 1968 to 2004 it was attached to Cârța. The coexistence with Cârța caused a slow atrophy both in the infrastructural situation of the village and in the state of the local society. In a referendum in 2003, people in both villages decided that Tomești would become independent again.

By 2004, the village's road network and public institutions were in a state of extreme deterioration. The park, the council house and the house of culture were neglected (the roof of the latter collapsed). It would not have been possible to implement the improvements on its own, the leadership of the village moved in the direction of financial resources. The new management started work under difficult circumstances but was able to make significant improvements. These included the commissioning of the town hall, the construction of the water and sewage network, the tidying up of the culture house, the maintenance of the field roads, the football field and public lighting and the railway station.

\section{ANALYSIS OF THE COMMUNITY LIFE, THE SOCIAL CAPITAL AND ANOMIE}

During the questionnaire interviews, we asked questions about trust and anomie. Three basic types of trust are commonly distinguished in the literature: general, strategic, and institutional trust. General trust is trust in people 
we don't know, it's based on empathy. In contrast, strategic trust is based on experience. Such as trust in family members, friends, colleagues. Confidence in the institutions has now is only addressed indirectly.

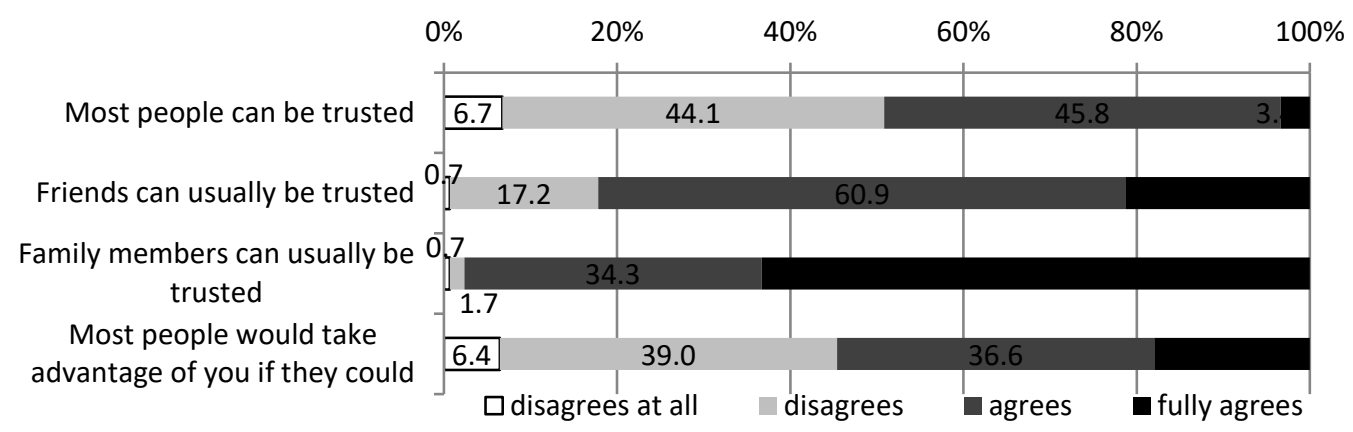

Figure 1. General and strategic trust in Tomești

Source: Questionnaire survey of the 2019 village research camp in Tomești

The strength of social capital was thus judged by measuring trust. In Tomești both the level of general and strategic trust is relatively high. Nearly half of those surveyed also trust strangers, not feeling they would take advantage of them. Trust in friends is common to more than $80 \%$ of respondents, but family members trust people almost without exception (Figure 1). Compared to the results of research in other villages, it can be concluded that the general trust in Tomești is high, although not the highest measured value. Trust in friends is also high, but lower than the average of the settlements analyzed in Hungary so far. At the same time, trust in family members is the highest among the settlements studied. Overall, the level of trust is high in the community and its pattern presupposes a degree of conservative value system.

Anomie means abnormality; the individual in a given situation does not know what to do, which norm to follow. Anomie can be caused by the weakening of existing norms, the spread of new norms, or the co-existence of several systems of norms. In anomic societies social capital is also weaker because norms are also important components of social capital.

We made four different statements about anomie (Table 2). The first statement - "Man lives from one day to the next; there is no point in making plans." - In the case of Tomești, three quarters of the respondents did not agree with this statement. This is a rather favourable value; the response was slightly influenced by the age, education and marital status of the respondents. In the case of the statement "Everything changes so fast, you don't even know what to believe." the situation was almost the opposite, the vast majority of respondents (71\%) agreed. This opinion was slightly influenced by age and education. Here the answers are similar to the answers of the examined Transylvanian villages, but the proportion of those who agree is higher than the proportions in Hungary. In the case of orientation in life, the answers are already similar to the Hungarian villages (54\%). Respondents' age and education had a small effect on responses. The importance of the role of the family has already been revealed. Almost without exception (98\%), respondents believe they can count on their spouse or family. This is the highest proportion among the studied settlements. Overall, the community of Tomești cannot be called anomic; its biggest problem is the interpretation and understanding of the rapidly changing world around people, as well as orientation in life.

Table 2. Proportion of those who agree with the following statements in Tomești (\%)

\begin{tabular}{lc}
\hline Statements & Agreed \\
\hline Man lives from day to day, there is no point in making plans. & 25,6 \\
Everything changes so fast; you don't even know what to believe. & 70,7 \\
Nowadays, I can barely navigate the things of life. & 54,9 \\
If I have a problem, I can count on my spouse or family. & 98,3 \\
\hline Source: Questionnaire survey of the 2019 village research camp in Tomești &
\end{tabular}

Based on the interviews, it seems that decisions are made in a narrow circle in the village, despite the fact that there are also village rallies and street rallies: "the management starts projects and they implement them" or "local politics is one-sided, conservative", and "multiple opinions should appear before decisions are made". Regarding local politics, we heard the following opinion: "party loyalty is more important than the interest of the community... we are not talking about what is good for us, but about what is good for the organization". 
Official civil activity is quite low in Tomești. One-tenth of the people living in the village are members of some kind of NGO. This value is quite low, even if there are several unofficial NGOs in the village. The Csonkatorony Folk Dance Ensemble and Orchestra were founded in 2004. Wind music orchestra, with more or less interruptions, was an integral part of the cultural life of the village. Re-creating the tradition, the Tomești Youth Wind Orchestra was formed in 2008 from students of the local primary school. Youth organizations include the Tomești's Youth for the Community Association and the Judo Association (https://www.csikszenttamas.ro/web/).

\section{DEVELOPMENT PROBLEMS AND VISIONS}

One of the most important questions of our questionnaire survey was what problems hinder the development of the settlement or adversely affect the quality of life of the locals (Table 3). The responses show that infrastructure problems are still the most important (14\%). However, these are closely followed by problems with community functioning (13\%). This is also closely followed by opinions on littering and pollution, and only then by the lack of jobs. Youth vandalism, public safety, wood theft and other behavioural problems were placed in a separate category.

Table 3. Distribution of problems mentioned by respondents in Tomești (\%)

\begin{tabular}{lll}
\hline Problems & $\mathbf{\%}$ \\
\hline 1. & infrastructure (condition of gas supply, roads, field roads) & 14,0 \\
2. & lack of cohesion, carelessness, weak community, communication problems & 13,3 \\
3. & littering, pollution, the condition of Olt river & 11,9 \\
4. & lack of jobs, unemployment, (labour shortage) & 10,6 \\
5. & vandalism of young people, public safety, wood theft, behavioural problems & 9,1 \\
6. & surveying problems, public tenure & 8,5 \\
7. & lack of entertainment, programs, confectionery, restaurant & 7,8 \\
8. & no problems & 6,1 \\
9. & emigration of young people, demographic problems & 5,1 \\
10. & livelihood problems, health problems, day care for the elderly & 5,1 \\
11. & others & 3,1 \\
12. & mayor, municipality, local leaders & 2,7 \\
13. & bears & 2,4 \\
\hline
\end{tabular}

We thought that the development proposals of the people living in the village would provide an answer to the mentioned problems. This was not the case; a quarter of respondents (Table 4) clearly made suggestions for the development of tourism, local attractions and local hospitality. This is followed by proposals for economic development (points 2 to 4 ), which together (36\%) would also precede tourism. In the proposals, the boost of community and cultural life (8.8\%) and the development of infrastructure and village image are not emphasized (7.8\%). Although the confectionery shop was mentioned by many, the creation of entertainment and sports opportunities alone received only two percent. Pessimistic opinions were not typical (3.4\%).

In January 2020, we presented the preliminary results of the village research camp in the renewed mayor's office. After the presentations, we asked participants to articulate how they would like to see Tomești fifteen years from now and how this vision could be achieved. With the help of group work, the vision of the village can be summarized below. There is no order between each point:

- A cleaner, more orderly village (picture), nurturing traditions, preserving identity (e.g. using the Székely flag),

- Developed and well-functioning local infrastructure (road, field road, sidewalk, water, sewage, gas network),

- A high degree of cooperation between the mayor's office, the school, the church and the house of culture,

- The number of enterprises is multiplying, agricultural associations are operating, local products can be bought in the busy local market, the assessment of public ownership is favourable, and the processing of local products is realized,

- Guest workers working abroad return home start businesses and create jobs.

- Strong rural tourism, with advanced services (e.g. confectionery shop), foreign language-speaking hosts.

The need for a bar or patisserie with higher services is clear, but it's a business issue, the entrepreneur needs to see the opportunity in it. In order to change the littering, vandalism and village image, community cooperation is 
needed. Based on the interviews, we can say that people need to be addressed personally, then they are willing to help.

Table 4. Distribution of development suggestions of the respondents (persons, percentage)

\begin{tabular}{llll}
\hline & Suggestions & $\mathbf{N}$ & $\mathbf{\%}$ \\
\hline 1 & Tourism, hospitality development, confectionery shop, restaurant development, & 73 & 24,8 \\
& Feneketlen Lake, Csonkatorony development & 42 & 14,3 \\
2 & Job creation & 34 & 11,6 \\
3 & Keeping young people at home, calling them home & 30 & 10,2 \\
4 & Development of agriculture, support of farmers & 26 & 8,8 \\
5 & Better community, boosting cultural life & 23 & 7,8 \\
6 & Optimistic opinions, the village will develop & 22 & 7,5 \\
7 & Infrastructure development, village image improvement & 11 & 3,7 \\
8 & Change of management, supportive management attitude, use of application & 10 & 3,4 \\
& opportunities & 10 & 3,4 \\
9 & Pessimistic opinions, no solution & 7 & 2,4 \\
10 & Other & 6 & 2,0 \\
11 & Retirement home, retirement club, day care for elderly & 6 \\
12 & Creation of entertainment and sports opportunities & & \\
\hline
\end{tabular}

Source: Questionnaire survey of the 2019 village research camp in Tomesti

Without cooperation between settlements, it is not possible to develop a settlement or countryside effectively. For a long time there was competition between the settlements of Felcsík, but they already realized that together they could work better. The co-operation between the settlements takes place primarily within the framework of the Felcsík Micro-Regional Association. The co-operation is good, not only the leaders of the settlements come together officially. At the same time, the framework of the Ciuc LEADER Action Group is too extensive for cooperation, according to the locals.

\section{CONCLUSIONS}

Tomești's development has been determined for centuries by its natural conditions, geographical location and infrastructural position. Natural factors provided opportunities primarily for forestry, but with the decline of forests, pasture farming and dairy cattle farming came to the fore. Among the political factors we should mention the world wars, the multiple changes of empire and decades of state socialism. At the same time, the role of the settlement was devalued as its independence ceased. The new era began in the village in 2004, when it regained its independence and the newly elected mayors and councillors started to work with a great impetus. The settlement could perhaps be characterized as being on the way. The disadvantages of the past have been processed in several ways, but the spectacular development has not yet begun.

We found that neither the external (infrastructural, natural) nor the internal (community-social) conditions are favourable. The functioning of the local community is well indicated by the fact that the informal economy is very widespread, the members of the community work closely together on a daily basis. Compared to previous village research, people are the happiest in the surveyed settlement. At the same time, trust in family members was also the highest, but the degree of anomie was quite low.

The situation differs when something should be done for the whole community. Respondents identified a lack of community cohesion, carelessness, a weak community, and a communication problem as one of the most important problems. We believe that while improvements in infrastructure and the state of the environment require mainly expertise, perseverance and resources, the development of the local community requires much more time, attention and patience.

Certainly there is a need for the development of the community, as a strong local economy requires a strong local community. The survey and conversations with the locals also outlined the vision of the settlement. Part of the vision is to create a liveable, modern village where the infrastructure is developed, the street scene is tidy and clean, local public institutions work together, farms are run by a large number of local entrepreneurs, farmers sell their produce at the local market and the up to now hidden rural tourism will emerge and strengthen.

Village research is not the same as village research. Accordingly, we can only compare our own results with those of previous village camps. At the same time, the growing number of our own practical experiences increasingly confirms our conclusions. In the future, it will be the main task for us to draw general conclusions and prepare summary studies. 
Author Contributions: T.F. designed the research framework, wrote the paper; D.K. Collected the data and wrote the paper; D.M. Contributed to the analysis.

\section{Funding Source:}

This research was funded by Bethlen Gábor Fund Management Co.

\section{Acknowledgments}

This research did not receive any specific grant from funding agencies in the public, commercial, or not-for-profit sectors.

\section{Conflicts of Interest}

The authors declare that they do not have any conflict of interest.

\section{REFERENCES}

1. Bíró Z (2002). Analysis of function of the local community in Madaras, KAM - Regional and Antropological Research Center, Miercurea Ciuc.

2. Bourdieu P (1997). The forms of capital. In: Angelus R (ed). Components of social stratification. Új Mandátum, Budapest, Hungary, pp: 156-177.

3. Bözödi Gy (1985). Székely cares. Budapest, Magvető Kiado.

4. Csák L (2015). Development strategy of Tomesti, Harghita county (2015-2020), Planificatio Miercurea Ciuc.

5. Farkas E (2019). The happiness map of Szeklerland is being prepared - this is what you can know about the survey so far https://www.maszol.ro/index.php/tarsadalom/109729-keszul-szekelyfold-boldogsagterkepe-eztlehet-eddig-tudni-a-felmeresr-l.

6. Farkas T, Kassai Zs (eds), (2014). Zsobok studies. Szent István Egyetemi Kiado, Gödöllő.

7. Farkas T, Kenderfi M (eds), (2015). Cserhátszentistván studies. Szent István Egyetemi Kiadó Gödöllő.

8. Farkas T, Kolta D (eds), (2017). Bátya studies. Szent István Egyetemi Kiadó, Gödöllő.

9. Farkas T, Kolta D (eds), (2018). Körösfő studies. Szent István Egyetemi Kiadó Gödöllő.

10. Füzér K, Gerő M, Sik E, Zongor G (2005). Opportunities to increase social capital through development policy instruments. Social impacts of development policy 4. TÁRKI, Budapest. Downloaded: 2011.07.13. http://www.tarki.hu/adatbank-h/kutjel/pdf/a768.pdf.

11. Gusti D (1976). The theory of sociological monograph. Kriterion, Bucharest.

12. Kulcsár L, Varga N, Obádovics Cs (2013). Informal economic behaviors and favoritism services in an interethnic village of Erdővidék. Gazdaság \& Társadalom.

13. Kulcsár L (2017). Theoretical approach to rural development: regional and cultural contexts.

14. Orbán B (1868). Description of Szeklerland - In terms of history, archeology, natural history and folklore. Panda and Frohna, Pest.

15. Sándor Sz (2005). Tomești - The heritage of Csonkatorony. F\&F International Ltd. Gheorgheni.

16. Székely KK (2016). Types of settlements in the Ciuc Basin and their marketing analysis (PhD. dissertation). Szent István University, Gödöllő.

17. Zólyomi GV (2000). What is sad is sleeping in me. Új ember, 38.

18. Homepage of Tomești. Available from: https://www.csikszenttamas.ro/web/

19. http://csikleader.ro/index.php/hu/helyi-fejlesztesi-strategia/ 